\title{
Health literacy and optimizing education materials in a surgical population
}

\author{
Eline Mariose Dijkman*1, Jobbe Pierre Lucien Leenen ${ }^{1}$, Remco Matthijs Koorn ${ }^{1}$, Diana Wilmink ${ }^{2}$ \\ ${ }^{1}$ Surgery Department, Isala, Hospital, Zwolle, the Netherlands \\ ${ }^{2}$ Lectorate Healthy Cities, Windesheim University of Applied Sciences, Zwolle, The Netherlands
}

Received: May 1, 2020

DOI: $10.5430 /$ jnep.v10n9p72
Accepted: May 24, 2020

Online Published: June 16, 2020

\begin{abstract}
Objective: The aim is to examine and compare the level of health literacy (HL) amongst surgical vascular and abdominal patients and measuring the understandability and actionability of current and optimized education materials.

Methods: A cross-sectional design was utilized. Patients undergoing abdominal or vascular surgery, were included for measuring HL with the Newest Vital Sign Dutch (NVS-d) tool. The Dutch version of the Patient Education Materials Assessment Tool (PEMAT) was used to measure the understandability and actionability of current and optimized patient education materials.

Results: A total of 101 patients were included, of those 54 (53.5\%) have limited HL. Patients with limited HL were significantly older $(p<.001)$, lower educated $(p<.001)$, and had a higher ASA status $(p=.005)$ and Charlson Comorbidity Index score $(p<.001)$. The occurrence of limited HL differed significantly $(p=.046)$ between abdominal versus vascular patients. The understandability varied between $24 \%-59 \%$ and the actionability between $40 \%-67 \%$ of the current education materials. The optimized education materials had a understandability score of $86 \%$ and a actionability score of $100 \%$.

Conclusions: The high prevalence of inadequate HL emphasizes the importance of nursing and medical staff providing clear information to enable shared decision-making. Besides, it is necessary to evaluate current education materials and optimize these materials according to the level of health literacy to provide health information that is understandable.
\end{abstract}

Key Words: Surgical patients, Education materials, NVS-d, Health literacy, Health Literacy

\section{INTRODUCTION}

Recently, health literacy gained much attention by reason of the major consequences for patients. Health literacy is defined as 'the degree to which individuals have the capacity to obtain, process, and understand basic health information and services needed to make appropriate health decisions'. ${ }^{[1]}$ Nearly $36.0 \%$ of adults in the U.S. have low health literacy. ${ }^{[2]}$ In Europe, a study in eight countries showed that approximately $47.6 \%$ of the adults have inadequate or problematic health literacy. ${ }^{[3]}$ In the Netherlands, the prevalence of inadequate and low health literacy is $29.0 \%$. Financial deprivation is shown to be the strongest predictor of inadequate health literacy, followed by social status, educational level, and age. ${ }^{[3]}$

Previous research showed that inadequate health literacy effects the ability to understand basic medical instructions and the ability to make appropriate health-related decisions. ${ }^{[4]}$ Patients with inadequate health literacy have less knowledge about their medical condition, and experience more difficulties to communicate with health care professionals and to manage their illness. ${ }^{[5]}$ Additionally, various studies showed the effects of inadequate health literacy, namely an increased

*Correspondence: Eline Mariose Dijkman; Email: e.m.dijkman@isala.nl; Address: Surgery Department, Isala, Hospital, Zwolle, the Netherlands. 
number of hospitalizations and re-hospitalizations, and a higher mortality and premature birth rate. ${ }^{[6-8]}$ Patients with low health literacy are more likely to suffer from chronic diseases, such as cancer, heart disease, diabetes, and respiratory disease. Consequently, healthcare costs are improperly high in these patients. ${ }^{[8,9]}$

Nowadays, complex health information and health-related decisions can be overwhelming to patients. However, health care professionals barely take this into account and instead use technical medical jargon, acronyms, and statistical estimates in their communication with patients. ${ }^{[10]}$ Thus, the problem is a combination of the extensive volume of information for the patient to understand and an insufficient ability to comprehend this.

Especially in perioperative patients health literacy plays an important role. Next to health literacy skills to understand the provided health information, numeracy skills are required in making decisions regarding to surgical procedures. Commonly, patients are expected to follow pre- and postoperative advice, but previous studies show that low health literacy negatively affects a patient's understanding of perioperative instructions, ${ }^{[11]}$ general consent forms, ${ }^{[12,13]}$ prescription labels, ${ }^{[14,15]}$ and appointment schedules. ${ }^{[14]}$ Insufficient understanding can result in adverse outcomes, delays, or even the cancellation of surgical procedures. ${ }^{[16,17]}$ Awareness of the health literacy level of surgical patients may, therefore, be important in providing comprehensible medical information, facilitating shared decision-making, and increasing patient satisfaction.

A recent study revealed that in a group of patients undergoing abdominal surgery, $6.9 \%$ had low, and $19.7 \%$ intermediate, health literacy. ${ }^{[18]}$ Other studies have stated a range of low health literacy of $39 \%-77 \%$ among patients undergoing vascular surgery. ${ }^{[19-21]}$ It should be noted, however, that differences in the measurement methods and instruments used in assessing health literacy makes comparison between surgical populations difficult. Unfortunately, knowledge about differences between health literacy levels in various surgical populations is poor. Besides, previous work has focused primarily on measuring health literacy in the outpatient clinic. The prevalence of inadequate health literacy of patients on nursing wards remains unclear. Moreover, current health education is often not created based on the health literacy levels of patients. Therefore, it is necessary to gain insight in the understandability of current education materials and to optimize the education materials based on the capacity of the population.

First, the purpose of this study is to examine the level of health literacy amongst surgical patients and to compare the level of health literacy between vascular and abdominal surgical patients. Second, this paper focuses on measuring the understandability and actionability of current and optimized education materials.

\section{METHODS}

\subsection{Study design}

A cross-sectional design was utilized and reported in accordance with the "Strengthening the Reporting of Observational Studies in Epidemiology" statement. ${ }^{[22]}$ The study was a quantitative descriptive study. Surveys were used for data collection.

\subsection{Setting and participants}

Patients admitted to the surgical ward of a tertiary hospital in the Netherlands were recruited between February 2018 and February 2019. Study subjects were included if they fulfilled the following criteria: vascular or abdominal patients, undergoing elective surgery or admitted at a surgical nursing ward, being able to speak and read the Dutch language. Potential subjects who met any of the following criteria were excluded, to prevent bias: participation in another, conflicting, study; diagnosis with cognitive impairments; undergoing surgery within $<2 \mathrm{~h}$ of admission; being $<24 \mathrm{~h}$ postoperative; or experiencing moderate to severe postoperative pain at the point of potential participation (Numeric Rating Scale $\geq 4$ ), in accord with hospital policy.

A convenient sampling method was used: patients were assessed when admitted to the surgical nursing ward, and data collection performed during or after the regular admittance interview. No previous data was available for sample-size calculation; however, a study size of approximately 100 patients was deemed valid for distinguishing differences between the two surgical groups.

\subsection{Variables}

\subsubsection{Newest Vital Sign}

The primary outcome was the level of health literacy of vascular and abdominal surgical patients as assessed by the free screening tool Newest Vital Sign Dutch (NVS-D). The NVS was validated in the United States for identifying people with limited health literacy. ${ }^{[23]}$ The NVS has been adapted and validated for use in other languages and countries, including the Netherlands. ${ }^{[23]}$

The NVS-d instrument (see Appendix A) was carried out as Weis earlier described in the study of the validation of the NVS. ${ }^{[24]}$ The questions of the NVS-d were asked as described in appendix A. All researchers in our study received prior training in use of the NVS-D tool, to increase inter-rater reliability. The screenings were executed at quiet times on 
the ward, and help by others was not permitted. Repetition of questions was allowed. Patient were allowed to use a calculator. With 0 to 1 correct answers, people are scored as having a high likelihood (50\% or more) of limited health literacy. With 2 to 3 correct answers, a person has a possibility of limited health literacy. A score of 4 to 6 almost always indicates adequate health literacy using the Test of Functional Health Literacy in Adults as the reference standard. ${ }^{[24]}$

\subsubsection{Patient Education Materials Assessment Tool}

The secondary outcome was the understandability and actionability of current and optimized patient education materials. The second screening tool used in this research was the Dutch version of the Patient Education Materials Assessment Tool (PEMAT) (see Appendix B). The PEMAT is a systematic method to evaluate and compare the understandability and actionability of patient education materials. ${ }^{[25]}$ Understandability in the PEMAT was defined as: patient education materials are understandable when consumers of diverse backgrounds and varying levels of health literacy can process and explain key messages. Actionability was defined in the PEMAT as: Patient education materials are actionable when consumers of diverse backgrounds and varying levels of health literacy can identify what they can do based on the information presented. The PEMAT was developed under contract to Agency for Healthcare Research and Quality (AHRQ) by a research team working with a panel of experts in health literacy, content creation, patient education, and communication. PEMAT items were based on items from existing instruments and concepts in guides to assess and develop patient education materials. The PEMAT demonstrated strong internal consistency, reliability, and evidence of construct validity. ${ }^{[25]}$ The PEMAT includes items 1-12 and 15-19 for understandability and items 20-26 for actionability. ${ }^{[26]}$ The evaluation of patient education materials was done independently by three researchers. After discussing the actionability and understandability was evaluated of each education material.

\subsubsection{Baseline characteristics}

In addition, the following baseline characteristics were obtained through access to the patient's records: age, gender, migration background, language, educational level, admission type, surgical specialism, medical procedure, American Society of Anesthesiologists (ASA) status, and their Charlson Comorbidity Index (CCI) score. ${ }^{[27]}$ These were measured because of their possible influence on levels of health literacy.

\subsection{Data analysis}

All analyses were performed with IBM SPSS Statistics 25.0 (IBM Armork, New York, USA) with a two-sided p-value of 0.05 deemed significant. Normally distributed data were presented by means and standard deviations. When data were not normally distributed, continuous variables were described by medians and inter-quartile ranges of Q1 to Q3 (IQR). Dichotomous and categorical data were described using frequencies and percentages. Every parameter was checked for normality with the Shapiro-Wilk test and visually by use of a histogram. Data were stratified by surgical specialism, vascular or abdominal. Based on normality, an independent $t$-test or Mann-Whitney $\mathrm{U}$ test was conducted between the two groups.

\subsection{Ethical issues}

The Medical Ethics Review Committee of Isala stated waived the need for ethical approval (protocol no. 190315). The study was conducted according to the principles of the Declaration of Helsinki 20136. ${ }^{[28]}$ Patients were given time to decide if they want to participate and informed consent was gathered. Subjects were not compensated for participation.

\section{RESULTS}

A total of 122 patients were approached for inclusion in the study. Of these, 21 (17.2\%) were excluded based on exclusion criteria $(n=8)$ or declined to participate $(n=13)$. The reasons for exclusion were: cognitive impairment $(n=5)$; being unable to speak and read the Dutch language $(n=3)$. Reasons for declining to participate were: fatigue $(n=11)$; being unable to understand the study's goal $(n=2)$.

Of the 101 included patients, 70 (69.3\%) were elective admissions to the hospital. The group's median age was 68 years (IQR 60-74) and 60 participants (59.4\%) were male. All participants were native Dutch. Regarding the ASA scores, $52.2 \%(n=47)$ of the participants scored ASA2 and $33.3 \%$ $(n=30)$ scored ASA3. The median score for the CCI was 5 (IQR 3-6).

A total of 51 participants were undergoing abdominal surgery, and 50, vascular surgery (see Table 1). Of the baseline characteristics, ASA status was shown to be significantly different between the two surgical groups $(p<.001)$.

Medical procedures in the abdominal surgery group included colorectal $(n=24)$, pancreatic $(n=8)$, and hepatic $(n=2)$ resections. The other patients were admitted because of infection ( $n=8)$, fundoplication $(n=3)$, diagnostic surgery ( $n$ $=3)$, appendectomy $(n=2)$ or cholecystectomy $(n=1)$.

In the vascular surgery group, patients were admitted for peripheral arterial angioplasty, stenting, or bypass surgery ( $\mathrm{n}$ $=23)$, abdominal aortic aneurysm $(n=12)$, infection $(n=7)$, lower extremity amputations $(n=5)$, or carotis endarterectomy $(n=3)$. 
Table 1. Baseline characteristics and NVS-D scores

\begin{tabular}{|c|c|c|c|}
\hline $\begin{array}{l}\text { Baseline characteristics } \\
(\mathrm{N}=101)\end{array}$ & $\begin{array}{l}\text { Abdominal patients } \\
(\mathrm{N}=51)\end{array}$ & $\begin{array}{l}\text { Vascular patients } \\
(\mathrm{N}=50)\end{array}$ & $p$-value \\
\hline Age (median, IQR) & $68(56-73)$ & $70.5(62-76)$ & .063 \\
\hline \multicolumn{4}{|l|}{ Sex $(n, \%)$} \\
\hline Male & $27(52.9)$ & $33(66)$ & \multirow[t]{2}{*}{.225} \\
\hline Female & $24(47.1)$ & $18(34)$ & \\
\hline \multicolumn{4}{|l|}{ Educational level (n, \%) } \\
\hline Low & 17 (33.3) & $26(52)$ & \multirow{3}{*}{.181} \\
\hline Middle & $21(41.2)$ & $15(30)$ & \\
\hline High & $13(25.5)$ & $9(18)$ & \\
\hline \multicolumn{4}{|l|}{ Admission type } \\
\hline Elective & 37 (72.5) & $33(66)$ & \multirow{2}{*}{.522} \\
\hline Emergency & $14(27.5)$ & $17(34)$ & \\
\hline \multicolumn{4}{|l|}{ ASA } \\
\hline 1 & $9(19.6)$ & $3(6.8)$ & \multirow{4}{*}{$.000^{*}$} \\
\hline 2 & $31(67.4)$ & $16(36.4)$ & \\
\hline 3 & $6(13.0)$ & $24(54.5)$ & \\
\hline 4 & $0(0)$ & $1(2.3)$ & \\
\hline CCI & $4(2-6)$ & $5(3-6)$ & .333 \\
\hline \multicolumn{4}{|l|}{ Read } \\
\hline Yes & $27(52.9)$ & $35(70)$ & \multirow[t]{2}{*}{.103} \\
\hline No & $24(47.1)$ & $15(30)$ & \\
\hline \multicolumn{4}{|l|}{ NVS-D } \\
\hline Score (median, IQR) & $5(2-6)$ & $2(1-4)$ & \multirow{3}{*}{$\begin{array}{l}.037 * * \\
.046^{*}\end{array}$} \\
\hline Limited & $22(43.1)$ & $32(64.0)$ & \\
\hline Adequate & 29 (56.9) & $18(36.0)$ & \\
\hline
\end{tabular}

*significant with $p<.05$ with Fisher's Freeman Halton Exact test; **significant with $p<.05$ with Mann-Whitney U-test

\subsection{Health literacy}

Of the 101 surgical patients, a total of 54 (53.5\%) patients scored 3 correct answers or less according to the NVS-d (see Table 1). Patients with limited health literacy were significantly older $(p<.001)$, had a lower educational level $(p<$ $.001)$, and had a higher ASA status $(p=.005)$ and CCI score $(p<.001)$. Moreover, these patients chose significantly more often to have the text read out aloud to them, rather than reading it themselves $(p<.001)$. No significant differences in health literacy were found based on gender, admission type, or oncological versus non-oncological status (see Table 2).

When stratified by surgical specialism, the median score for the NVS-D was 5 (IQR: 2-6) in the abdominal surgery patients, of whom $22(43.1 \%)$ patients scored 3 correct answers or less according to the NVS-d. Within the vascular surgery group, the median NVS-D score was 2 (IQR: 1-4) and 32 patients (64\%) scored 3 correct answers or less according to the NVS-d. Both the median $(p=.037)$ and cut-off scores ( $p$ $=.046$ ) were significantly different between the two groups. Vascular patients gave an incorrect answer to Question 3 significantly more often (see Table 3 ) than the abdominal group. The NVS-d was read by the researchers for $52.9 \%$ of the patients $(\mathrm{n}=27)$ undergoing abdominal surgery and $70 \%$ of the patients $(n=35)$ undergoing vascular surgery. However, this difference was not significant $(p=.103)$.

\subsection{Understandability and actionability of patient edu- cation materials}

The results described above show that $53.5 \%$ of all the surgical patients scored 3 or less correct answers on the NVS-d. This suggests that more than half of the surgical patients experience difficulties with understanding patient education materials. Therefore, it is necessary to evaluate if the current education materials are suitable for this surgical population.

Four patient education materials about important nursing issues that are often used on the nursing ward were independently evaluated by two researchers (ED, JL). The current education materials about pain management, pressure ulcers, malnutrition and the usefulness of mobilization were evaluated using PEMAT.

The current education materials were combined to one education material that included all issues. Besides, the current patient education materials were optimized by a communi- 
cation professional, a medical illustrator, and using patients and health care professional's feedback. This resulted in an optimized education material about pain management, pressure ulcers, malnutrition and the usefulness of mobilization. Last, the optimized education material was evaluated by two independent researchers using PEMAT.
The understandability score varied between $24 \%-59 \%$ of the current education materials. Besides, the actionability score varied between 40\%-67\% (Tab. 4). The optimized education materials had a understandability score of $86 \%$ and a actionability score of $100 \%$.

Table 2. NVS-D scores stratified by level of health literacy

\begin{tabular}{|c|c|c|c|}
\hline & $\begin{array}{l}\text { Limited HL } \\
(N=54)\end{array}$ & $\begin{array}{l}\text { Adequate } \mathrm{HL} \\
(\mathrm{N}=47)\end{array}$ & $p$-value \\
\hline Age (median, IQR) & $73(66-76.3)$ & $63(55-70)$ & $.000 * *$ \\
\hline \multicolumn{4}{|l|}{ Sex $(n, \%)$} \\
\hline Male & 33 (61.1) & $27(57.4)$ & \multirow[t]{2}{*}{.839} \\
\hline Female & $21(38.9)$ & $20(42.6)$ & \\
\hline \multicolumn{4}{|c|}{ Educational level (n, \%) } \\
\hline Low & $33(61.1)$ & $10(21.3)$ & \multirow{3}{*}{$.000^{*}$} \\
\hline Middle & $13(24.1)$ & 23 (48.9) & \\
\hline High & 8 (14.8) & $14(29.8)$ & \\
\hline \multicolumn{4}{|l|}{ Admission type } \\
\hline Elective & 41 (75.9) & $29(61.7)$ & \multirow[t]{2}{*}{.136} \\
\hline Emergency & $13(24.1)$ & $18(38.3)$ & \\
\hline \multicolumn{4}{|l|}{ ASA } \\
\hline 1 & $3(6)$ & $9(22.5)$ & \multirow{4}{*}{$.005 *$} \\
\hline 2 & $23(46)$ & $24(60.0)$ & \\
\hline 3 & $23(46)$ & $7(17.5)$ & \\
\hline 4 & $1(2)$ & $0(0)$ & \\
\hline CCI & $5.5(4-7)$ & $3(2-6)$ & $.000 * *$ \\
\hline \multicolumn{4}{|l|}{ Read } \\
\hline Yes & $42(77.8)$ & $20(42.6)$ & \multirow[t]{2}{*}{$.000^{*}$} \\
\hline No & $12(22.2)$ & $27(57.4)$ & \\
\hline \multicolumn{4}{|l|}{ Oncological } \\
\hline Yes & $17(31.5)$ & $16(34)$ & \multirow[t]{2}{*}{.834} \\
\hline No & $37(68.5)$ & $31(66)$ & \\
\hline
\end{tabular}

*significant with $p<.05$ with Fisher's Freeman Halton Exact test; **significant with $p<.05$ with Mann-Whitney U-test.

Table 3. Distribution of answers at the NVS-D

\begin{tabular}{llll}
\hline Question & $\begin{array}{l}\text { Abdominal patients } \\
(\mathbf{N}=\mathbf{5 1}) \\
\text { (correct/incorrect) }\end{array}$ & $\begin{array}{l}\text { Vascular patients } \\
(\mathbf{N = 5 0 )} \\
\text { (correct/incorrect) }\end{array}$ & p-value \\
\hline Q1 & $32 / 19$ & $22 / 28$ & .074 \\
Q2 & $36 / 15$ & $29 / 21$ & .216 \\
Q3 & $30 / 21$ & $13 / 37$ & $.001^{*}$ \\
Q4 & $26 / 25$ & $17 / 33$ & .108 \\
Q5 & $33 / 18$ & $31 / 19$ & .838 \\
Q6 & $31 / 20$ & $24 / 26$ & .233 \\
\hline *significant with $p<.05$ with Fisher's Exact test
\end{tabular}

\section{Discussion}

This study shows that more than half $(53.5 \%)$ of the vascular and abdominal surgical patients have limited health literacy. Patients with limited health literacy were older, less educated, and diagnosed with more comorbidities. Besides, it is evident from the results that within the vascular patient population a significantly higher rate of patients with limited health literacy was present compared to abdominal patients.

Moreover, this study shows that the understandability and actionability of currently used education materials was poor. However, optimization of the current printed education materials resulted in increased understandability and actionability.

The results regarding to the overall percentages of limited health between various countries are substantial.3 For example, in the Netherlands the percentage of limited health literacy is reported to be $28.7 \%$, in the USA $36.0 \%$ and Bulgaria $62.1 \%$. Our study results, relating to the overall percentage limited health literacy level in surgical patients $(53.5 \%)$ differs considerably from the national average $(36.4 \%)$ in the Netherlands. This could be explained by the higher preva- 
lence of chronic diseases, higher age, and lower education level of surgical patients. These patient characteristics are associated with a lower health literacy level. ${ }^{[21,29]}$ Moreover, our results are in line with a study performed in the Netherlands, that detected a comparable incidence of low health literacy $(52 \%)$ in a large cohort of pharmacy visitors. ${ }^{[30]}$

Table 4. Understandability and actionability scores of education materials

\begin{tabular}{lll}
\hline Education material & Understandability (\%) & Actionability (\%) \\
\hline Current & & \\
Pressure ulcer & 24.0 & 67.0 \\
Malnutrition & 37.5 & 40.0 \\
Pain management & 59.0 & 67.0 \\
$\quad$ Mobilization & 38.5 & 40.0 \\
Optimized version & & \\
$\quad$ Combination of pressure ulcer/Malnutrition/pain & 86.0 & 100.0 \\
management/mobilization & & \\
\hline
\end{tabular}

Unlike Strijbos et al., who identified a prevalence of $76.7 \%$ of patients with limited health literacy, ${ }^{[21]}$ our study found a lower prevalence of patients with limited health literacy in vascular surgical patients (64.0\%). This discrepancy could be explained by a potential underestimation of patients with limited health literacy in our study by excluding illiterate patients and patients declining to participate because of fatigue caused by their surgery. However, in daily practice, these excluded patients are also receiving education materials to make health related decisions. Nonetheless, we did observe differences in the prevalence of limited health literacy between vascular surgical patients and abdominal surgical patients. Our data cannot explain these differences, so further research with parameters such as lifestyle, smoking status and familiarity with health information would be of great interest.

Several health organizations assign the importance that health services should deliver health information in ways that are easy to understand and, as such, can improve health. Previous studies assessing the readability and actionability of patient education materials on multiple health topics report low scores on readability, actionability or both. ${ }^{[31-33]}$ The results of our study, showing low scores on readability and actionability of the current education materials delivered by nurses, are in line with these results. After evaluation using the PEMAT and optimization of the current education materials, the readability and actionability increased largely.

However, several limitations in this study should be considered. Firstly, the timing of the measurement process may have introduced selection bias, given the relatively high number of refusals to participate with 'fatigue' as the reason. In addition, it is important to recognize that patients feel ashamed about low literacy skills and illiteracy, this may result in avoiding challenging situations ${ }^{[34]}$ and participation in our study. Moreover, an unexpected phenomenon during data collection was that some patients related the questions of the NVS-D too much to their own diet. This resulted in difficulties of answering the questions and repeating the question more often for better understanding. Notably, there was specific difficulty with Question 3, which frequently required repeating by the researcher - possibly because of the length of the question. However, this instrument was chosen because it measures both reading comprehension and numeracy skills. ${ }^{[24]}$ Furthermore, it provides objective information on health literacy and is executed in a minimal time frame.

This study focused particularly on written education materials and not on tailoring the verbal communication of health professionals based on health literacy level of patients. Future research should focus on creating understandable education materials in combination with the communication of healthcare professionals. Besides, this study focused on surgical patients, especially vascular and abdominal patients. It would be beneficial for nurses to gain insight on the level of health literacy of specific populations on nursing wards to adapt their education materials accordingly.

The importance of providing information to a level generally comprehensible by the patient is clear from this study. As a further point, limited health literacy appears to be more prevalent in vascular surgical patients $(64.0 \%)$ than in abdominal surgical patients $(43.1 \%)$, which makes the case for extra attention when providing health information to this population. It is important that healthcare professionals take these results into account when providing patient education, gaining informed consent for medical interventions, or seeking the participation of the patient in shared decision-making. Especially because patients with all levels of health literacy would benefit from communication which is comprehensible and tailored for everyone personally. ${ }^{[35]}$ Eventually, pro- 
viding clear medical information results in higher patient satisfaction and more favorable health outcomes. ${ }^{[36,37]}$

\section{Conclusion}

The high prevalence of inadequate health literacy emphasizes the importance of nursing and medical staff providing clear information about the condition a patient is suffering from, as well as procedures, to enable shared decision-making. In addition, it is necessary to evaluate current education materials and optimize these materials according to the level of health literacy to provide health information that is understandable, and as such can improve health.

\section{ACKNOWLEDGEMENTS}

This work was supported by the Isala Innovation and Science fund [grant number RT/mw.18023].

\section{CONFlicts OF INTEREST Disclosure}

The authors declare that they have no competing interests.

\section{REFERENCES}

[1] Institute of Medicine. Health literacy: a prescription to end confusion Washington DC; 2004

[2] Ratzan SC, Parker RM. Introduction. Natl Libr Med Curr Bibliogr Med Heal Literacy. 2000.

[3] Sorensen K, Pelikan JM, Rothlin F, et al. Health literacy in Europe: comparative results of the European health literacy survey (HLS-EU). Eur J Public Health. 2015; 25(6): 1-6. PMid:25843827 https://doi.org/10.1093/eurpub/ckv043

[4] Smith SG, Curtis LM, Wardle J, et al. Skill set or mind set? Associations between health literacy, patient activation and health. PLoS One. 2013; 8(9): e74373. PMid:24023942 https ://doi .org/10 .1371/journal.pone.0074373

[5] Williams MV, Davis T, Parker RM, et al. The role of health literacy in patient-physician communication. Fam Med. 2002.

[6] Bostock S, Steptoe A. Association between low functional health literacy and mortality in older adults: longitudinal cohort study. BMJ 2012 Mar; 344: e1602. PMid:22422872 https://doi.org/10.1 $136 / \mathrm{bmj}$.e1602

[7] DeWalt DA, Berkman ND, Sheridan S, et al. Literacy and health outcomes: A systematic review of the literature. Vol. 19, Journal of General Internal Medicine. 2004; 1228-39. PMid:15610334 https://doi.org/10.1111/j.1525-1497.2004.40153.x

[8] Wolf MS, Gazmararian JA, Baker DW. Health literacy and functional health status among older adults. Arch Intern Med. 2005 Sep; 165(17): 1946-52. PMid:16186463 https://doi.org/10.1001/ archinte.165.17.1946

[9] Heijmans M, Zwikker H, van der Heide I, et al. NIVEL Kennisvraag 2016: Zorg op maat. Hoe kunnen we de zorg beter laten aansluiten bij mensen met lage gezondheidsvaardigheden? Utrecht; 2016.

[10] Smith SA. Patient education and literacy. In: Preventive medicine and Patient education. 2001; 266-90.

[11] Chew LD, Bradley KA, Flum DR, et al. The impact of low health literacy on surgical practice. Am J Surg. 2004 Sep; 188(3): 250-3 PMid:15450829 https ://doi.org/10.1016/j.amjsurg. 2004 .04 .005

[12] Zite NB, Wallace LS. Use of a low-literacy informed consent form to improve women's understanding of tubal sterilization: a randomized controlled trial. Obstet Gynecol. 2011 May; 117(5): 1160-6. PMid:21508756 https : //doi.org/10.1097/AOG.0b013e3182 $13 \mathrm{cbb} 1$

[13] LoVerde ME, Prochazka AV, Byyny RL. Research consent forms: continued unreadability and increasing length. J Gen Intern Med. 1989; 4(5): 410-2. PMid:2795264 https://doi.org/10.1007/ BF02599693
[14] Berkman ND, Sheridan SL, Donahue KE, et al. Low health literacy and health outcomes: an updated systematic review. Ann Intern Med. 2011 Jul; 155(2): 97-107. PMid:21768583 https: //doi .org/10.7326/0003-4819-155-2-201107190-00005

[15] Davis TC, Wolf MS, Bass PF 3rd, Middlebrooks M, Kennen E, Baker DW, et al. Low literacy impairs comprehension of prescription drug warning labels. J Gen Intern Med. 2006 Aug; 21(8): 847-51. PMid:16881945 https://doi.org/10.1111/j.1525-1497.20 $06.00529 . \mathrm{x}$

[16] Hovlid E, von Plessen C, Haug K, et al. Patient experiences with interventions to reduce surgery cancellations: a qualitative study. BMC Surg. 2013 Aug; 13: 30. PMid:23924167 https ://doi .or g/10.1186/1471-2482-13-30

[17] Toussi R, Fujioka K, Coleman KJ. Pre- and postsurgery behavioral compliance, patient health, and postbariatric surgical weight loss. Obesity (Silver Spring). 2009 May; 17(5): 996-1002. PMid:19165167 https ://doi.org/10.1038/oby.2008.628

[18] Wright JP, Moses K, Idrees K. Making the Case for Importance of Health Literacy in the Surgical Population. JAMA Surg. 2018 Aug; 153(8): 745-6. PMid:29710089 https://doi.org/10.1001/ja masurg. 2018.0673

[19] Wallace LS, Cassada DC, Rogers ES, et al. Can Screening Items Identify Surgery Patients at Risk of Limited Health Literacy? J Surg Res. 2007.

[20] Wallace LS, Ergen WF, Cassada DC, et al. Development and Validation of the Rapid Estimate of Adult Literacy in Vascular Surgery (REAL_VS). Ann Vasc Surg. 2009.

[21] Strijbos RM, Hinnen JW, van den Haak RFF, et al. Inadequate Health Literacy in Patients with Arterial Vascular Disease. Eur J Vasc Endovasc Surg. 2018 Aug; 56(2): 239-45. PMid:29891435 https://doi.org/10.1016/j.ejvs.2018.04.015

[22] von Elm E, Altman DG, Egger M, et al. The Strengthening the Reporting of Observational Studies in Epidemiology (STROBE) Statement: guidelines for reporting observational studies. Int J Surg. 2014 Dec; 12(12): 1495-9. PMid:25046131 https://doi.org/10.1016/j . ijsu.2014.07.013

[23] Fransen MP, Leenaars KEF, Rowlands G, et al. International application of health literacy measures: adaptation and validation of the newest vital sign in The Netherlands. Patient Educ Couns. 2014 Dec; 97(3): 403-9. PMid:25224314 https ://doi.org/10.1016/j.pe c. 2014.08 .017

[24] Weiss BD, Mays MZ, Martz W, et al. Quick assessment of literacy in primary care: The newest vital sign. Ann Fam Med. 2005.

[25] Shoemaker SJ, Wolf MS, Brach C. Development of the Patient Education Materials Assessment Tool (PEMAT): A new measure of understandability and actionability for print and audiovisual 
patient information. Patient Educ Couns. 2014. PMid:24973195 https://doi.org/10.1016/j.pec.2014.05.027

[26] Shoemaker SJ. The Patient Education Materials Assessment Tool (PEMAT) and User' s Guide. AHRQ Publ. 2014. https://doi.or $\mathrm{g} / 10.1037 / \mathrm{t} 37641-000$

[27] de Groot V, Beckerman H, Lankhorst GJ, et al. How to measure comorbidity. a critical review of available methods. J Clin Epidemiol. 2003 Mar; 56(3): 221-9.

[28] World Medical Association. World Medical Association Declaration of Helsinki. 2001; 79(4): 373-4. https : //doi .org/10.4414/fm s. 2001.04031

[29] van der Heide I, Rademakers J, Schipper M, et al. Health literacy of Dutch adults: a cross sectional survey. BMC Public Health. 2013 Feb; 13: 179. PMid:23445541 https://doi.org/10.1186/1471 $-2458-13-179$

[30] Koster ES, Philbert D, Bouvy ML. Health literacy among pharmacy visitors in the Netherlands. Pharmacoepidemiol Drug Saf. $2015 \mathrm{Jul}$; 24(7): 716-21. PMid:26016832 https://doi .org/10.1002/pds . 3803

[31] Lopez Ramos C, Williams JE, Bababekov YJ, et al. Assessing the Understandability and Actionability of Online Neurosurgical Patient Education Materials. World Neurosurg. 2019. PMid:31260846 https://doi.org/10.1016/j.wneu.2019.06.166
[32] Yiu A, Ng KK, Lee VW, et al. Evaluating the Understandability and Actionability of Web-Based Education Materials for Patients Taking Non-vitamin K Oral Anticoagulants. Ther Innov Regul Sci. 2019.

[33] Lipari M, Berlie H, Saleh Y, et al. Understandability, actionability, and readability of online patient education materials about diabetes mellitus. Am J Heal Pharm. 2019.

[34] Parikh NS, Parker RM, Nurss JR, et al. Shame and health literacy: the unspoken connection. Patient Educ Couns. 1996 Jan; 27(1): 33-9. https://doi .org/10.1016/0738-3991(95)00787-3

[35] Aboumatar HJ, Carson KA, Beach MC, et al. The impact of health literacy on desire for participation in healthcare, medical visit communication, and patient reported outcomes among patients with hypertension. J Gen Intern Med. 2013 Nov; 28(11): 1469-76. PMid:23690237 https://doi .org/10.1007/s11606-013-2466-5

[36] Kripalani S, Weiss BD. Teaching about health literacy and clear communication. J Gen Intern Med. 2006 Aug; 21(8): 888-90. PMid:16881953 https://doi.org/10.1111/j.1525-1497.20 $06.00543 . \mathrm{x}$

[37] Sitzia J, Wood N. Patient satisfaction: a review of issues and concepts. Soc Sci Med. 1997 Dec; 45(12): 1829-43. https ://doi.org/10 .1016/S0277-9536(97)00128-7 